\title{
Inertial gravity waves observed by a Doppler wind LiDAR and their possible sources
}

\author{
XiangHui Xue ${ }^{1,2,3,4^{*}}$, DongSong Sun ${ }^{1}$, HaiYun Xia ${ }^{1}$, and XianKang Dou ${ }^{1,5^{*}}$ \\ 1'Chinese Academy of Sciences Key Laboratory of Geospace Environment, University of Science and Technology of China, Hefei 230026, China; \\ ${ }^{2}$ Chinese Academy of Sciences Center for Excellence in Comparative Planetology, Hefei 230026, China; \\ ${ }^{3}$ Anhui Mengcheng Geophysics National Observation and Research Station University of Science and Technology of China, Hefei 230026, China; \\ ${ }^{4}$ Synergetic Innovation Center of Quantum Information \& Quantum Physics, University of Science and Technology of China, Hefei 230026, China; \\ ${ }^{5}$ Hefei National Laboratory for the Physical Sciences at the Microscale, University of Science and Technology of China, Hefei 230026, China
}

Key Points:

- IGWs obtained from a Doppler wind LiDAR

- IGWs in lower and upper stratosphere have different propagating features

- The different wave patterns are likely associated with the presence of lower and upper stratospheric jet streams

Citation: Xue, X. H., Sun, D. S., Xia, H. Y., and Dou, X. K. (2020). Inertial gravity waves observed by a Doppler wind LiDAR and their possible sources. Earth Planet. Phys., 4(5), 461-471. http://doi.org/10.26464/epp2020039

\begin{abstract}
In this paper, we use wind observations by a Doppler wind LiDAR near Delingha $\left(37.4^{\circ} \mathrm{N}, 97.4^{\circ} \mathrm{E}\right)$, Qinghai, Northwestern China to study the characteristics of inertial gravity waves in the stratosphere. We focus on 10-12 December 2013, a particularly interesting case study. Most of the time, the inertial gravity waves extracted from the LiDAR measurements were stationary with vertical wavelengths of about 9-11 km and horizontal wavelengths of about 800-1000 km. However, for parts of the observational period in this case study, a hodograph analysis indicates that different inertial gravity wave propagation features were present at lower and upper altitudes. In the middle and upper stratosphere ( 30-50 km), the waves propagated downward, especially during a period of stronger winds, and to the northwest-southeast. In the lower stratosphere and upper troposphere ( 10-20 km), however, waves with upward propagation and northeast-southwest orientation were dominant. By taking into account reanalysis data and satellite observations, we have confirmed the presence of different wave patterns in the lower and upper stratosphere during this part of the observational period. The combined data sets suggest that the different wave patterns at lower and upper height levels are likely to have been associated with the presence of lower and upper stratospheric jet streams.
\end{abstract}

Keywords: gravity waves; lidar; wind observations

\section{Introduction}

Atmospheric gravity waves play an important role in coupling between the lower and the upper atmosphere and greatly affect both the global energy budget and the general circulation (Fritts and Alexander, 2003). Gravity waves with frequencies close to the Coriolis frequency $f$ are referred to as inertial gravity waves. Inertial gravity waves are particularly important in the stratosphere, as breaking of these waves leads to the formation of air turbulence (Plougonven et al., 2003). Previous studies indicate that jet streams are a quantitatively important source of inertial gravity waves (e.g., O'Sullivan and Dunkerton, 1995; Guest et al., 2000; Plougonven et al., 2003; Vaughan and Worthington, 2007; Spiga et al., 2008;).

Correspondence to: X. H. Xue, xuexh@ustc.edu.cn

X. K. Dou, dou@ustc.edu.cn

Received 27 MAR 2020; Accepted 23 APR 2020.

Accepted article online 08 JUN 2020.

(C) 2020 by Earth and Planetary Physics.
Previous studies focusing on inertial gravity waves and their association with jets in the upper troposphere and lower stratosphere have mostly used radio soundings (e.g., Guest et al., 2000; Plougonven et al., 2003), mesosphere-stratosphere-troposphere (MST) radars (e.g., Thomas et al., 1999; Vaughan and Worthington, 2007), or numerical simulations (e.g., Spiga et al., 2008; Shutts and Vosper, 2011; Kim et al., 2016).

Atmospheric LiDARs are powerful tools that provide measurements of the middle and upper atmosphere. Above the stratopause, temperature and wind measurements of high temporal and vertical resolution can be obtained simultaneously with LiDARs, by exploiting metal fluorescent resonance scattering effects. These measurements are frequently used to study gravity wave propagation in the mesosphere and lower thermosphere (MLT) region (e.g., Liu AZ et al., 2013; Placke et al., 2013; Lu X et al., 2015, 2017; Kaifler et al., 2015; Chen $C$ et al., 2016). Below the mesopause, fluctuations in temperature or density are usually measured by Rayleigh/Raman-scattering LiDARs. These measurements 
are used to investigate gravity wave characteristics in the stratosphere and mesosphere (e.g., McDonald et al., 1998; Li T et al., 2010; Alexander et al., 2011; Kogure et al., 2017).

However, although wind observations would be very useful for studying inertial gravity waves in the stratosphere, observations made by Doppler LiDARs have been quite limited (Hertzog et al., 2001; Xia HY et al., 2012; Baumgarten et al., 2015; Zhao RC et al., 2017). For example, Hertzog et al. (2001) observed inertial gravity waves with upward energy propagation in the lower stratosphere at Haute-Provence, France. Baumgarten et al. (2015) reported on the first observation of persistent inertia gravity wave signatures in horizontal winds and temperatures up to $\sim 80 \mathrm{~km}$ using a Doppler Rayleigh LiDAR. Zhao RC et al. (2017) discussed typical characteristics of inertial gravity waves in the mid-latitude area of China using 3-year mobile Rayleigh Doppler LiDAR observations.

In this paper, we investigate a case study of inertial gravity wave observations and their association with lower and upper stratospheric jets using the same Doppler LiDAR system described by Zhao RC et al. (2016, 2017). The Doppler LiDAR system and other data used in this paper are described in Section 2. In Section 3, a comparison is shown between stratospheric winds observed by the LiDAR and a reanalysis data set. The characteristics of the observed inertial gravity waves from a hodograph analysis are provided in Section 4. In Section 5, possible sources of the observed inertial gravity waves are discussed. Conclusions are given in Section 6.

\section{Description of Observational and Reanalysis Data}

The Doppler LiDAR system of the University of Science and Technology of China (USTC) is based on the "double-edge technique", which obtains direct wind measurements using two Fabry-Perot interferometers (FPIs) covering thermally broadened molecular backscattered signals in the wings of the spectrum. The laser frequency is locked at $355 \mathrm{~nm}$ at one-minute intervals by another FPI with an accuracy of $1.8 \mathrm{MHz}$, which corresponds to a standard deviation error of $0.32 \mathrm{~m} / \mathrm{s}$ in the line of sight (LOS) wind velocity. The whole system consists of two similar, independent subsystems pointing in fixed LOS directions at $30^{\circ}$ zenith angle, which are orthogonal to each other in horizontal projection, to obtain both the zonal and the meridional winds. The USTC Doppler wind LiDAR is integrated on a truck for mobility. More details are described in Dou XK et al. (2014) and Zhao RC et al. (2016). The main parameters of the system are listed in Table 1.

The observations reported in this paper were collected on 10-12 December 2013 in Delingha $\left(37.4^{\circ} \mathrm{N}, 97.4^{\circ} \mathrm{E}\right)$, Qinghai, Northwestern China (see Figure 1). The horizontal wind in the 10 to $\sim 55 \mathrm{~km}$ range was retrieved by accumulating raw signals for 30 minutes and shifting every 2 minutes. The corresponding vertical resolution of the wind measurements is $0.2 \mathrm{~km}$ below $40 \mathrm{~km}$ and $1.0 \mathrm{~km}$ above $40 \mathrm{~km}$ (due to low signal to noise ratio; more details can be found in Zhao RC et al. (2016)). In general, the errors of the winds are $\pm 5 \mathrm{~m} / \mathrm{s}$ at $60 \mathrm{~km}, \pm 2 \mathrm{~m} / \mathrm{s}$ at $50 \mathrm{~km}$ and less than $\pm 1 \mathrm{~m} / \mathrm{s}$ at $\sim 40 \mathrm{~km}$. To achieve good accuracy, we focused on wind data below $\sim 50 \mathrm{~km}$ in this study.

The newly released ERA5 data set is the fifth generation of the
Table 1. Technical parameters of the USTC Doppler wind LiDAR system.

\begin{tabular}{|c|c|}
\hline \multicolumn{2}{|l|}{ Transceiver } \\
\hline Wavelength (nm) & 355 \\
\hline Pulse Energy (mJ) & 350 \\
\hline Laser 1/e Width (MHz) & 200 \\
\hline Repetition Rate $(\mathrm{Hz})$ & 50 \\
\hline \multicolumn{2}{|l|}{ Transceiver } \\
\hline Telescope aperture (m) & 1.0 \\
\hline Field of View (mrad) & 0.09 \\
\hline Zenith angle $\left({ }^{\circ}\right)$ & 30 or 0 \\
\hline Optical efficiency (\%) & 85 \\
\hline \multicolumn{2}{|l|}{ Receiver } \\
\hline $\mathrm{FSR}(\mathrm{GHz})$ & 12 \\
\hline FWHM (GHz) & 1.7 \\
\hline Edge channel separation (GHz) & 5.1 \\
\hline Peak transmission (\%) & 60 \\
\hline PMT quantum efficiency (\%) & 21 \\
\hline
\end{tabular}

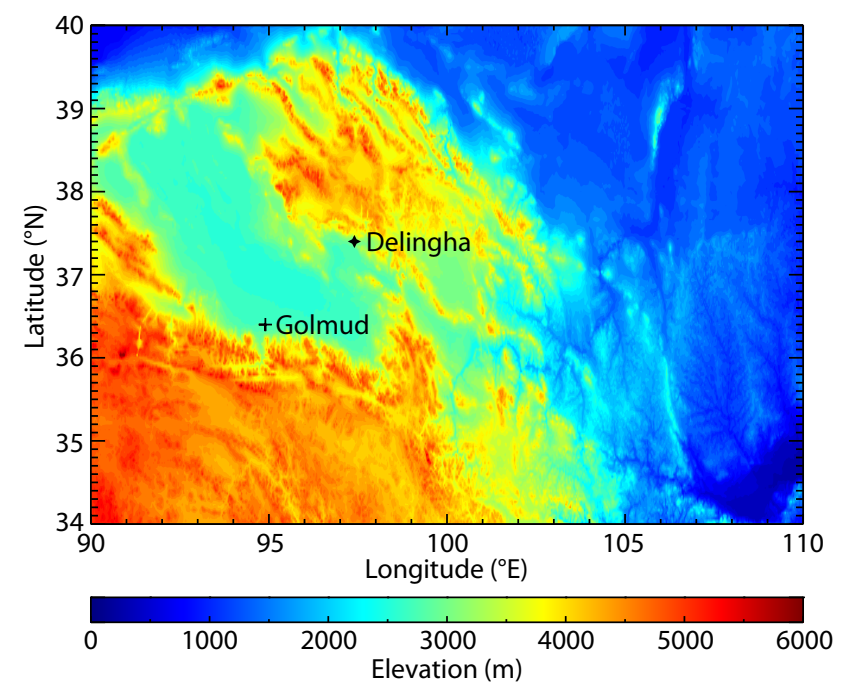

Figure 1. Overview of the orography around Delingha $\left(37.4^{\circ} \mathrm{N}\right.$, $\left.97.4^{\circ} \mathrm{E}\right)$. The location of Delingha is indicated by a star symbol. The location of Golmud $\left(36.4^{\circ} \mathrm{N}, 94.9^{\circ} \mathrm{E}\right)$, where meteorological sounding data were obtained, is indicated by a plus symbol.

European Center for Medium-Range Weather Forecasts (ECMWF) atmospheric reanalyses of the global climate. The data have an effective horizontal resolution of $30 \mathrm{~km}\left(\sim 0.3^{\circ}\right)$ and resolve the atmosphere using 137 levels from the surface up to a height of $80 \mathrm{~km}$. ERA5 provides significantly better spatial and temporal resolution than its predecessor, ERA-Interim (Hersbach and Dee, 2016). Here, daily ERA5 data with a temporal resolution of 1 hour are used for comparison with the LiDAR observations.

\section{LiDAR Observations and Comparison of Wind Data}

Figure 2 shows a comparison of daily mean winds on 10 Decem- 

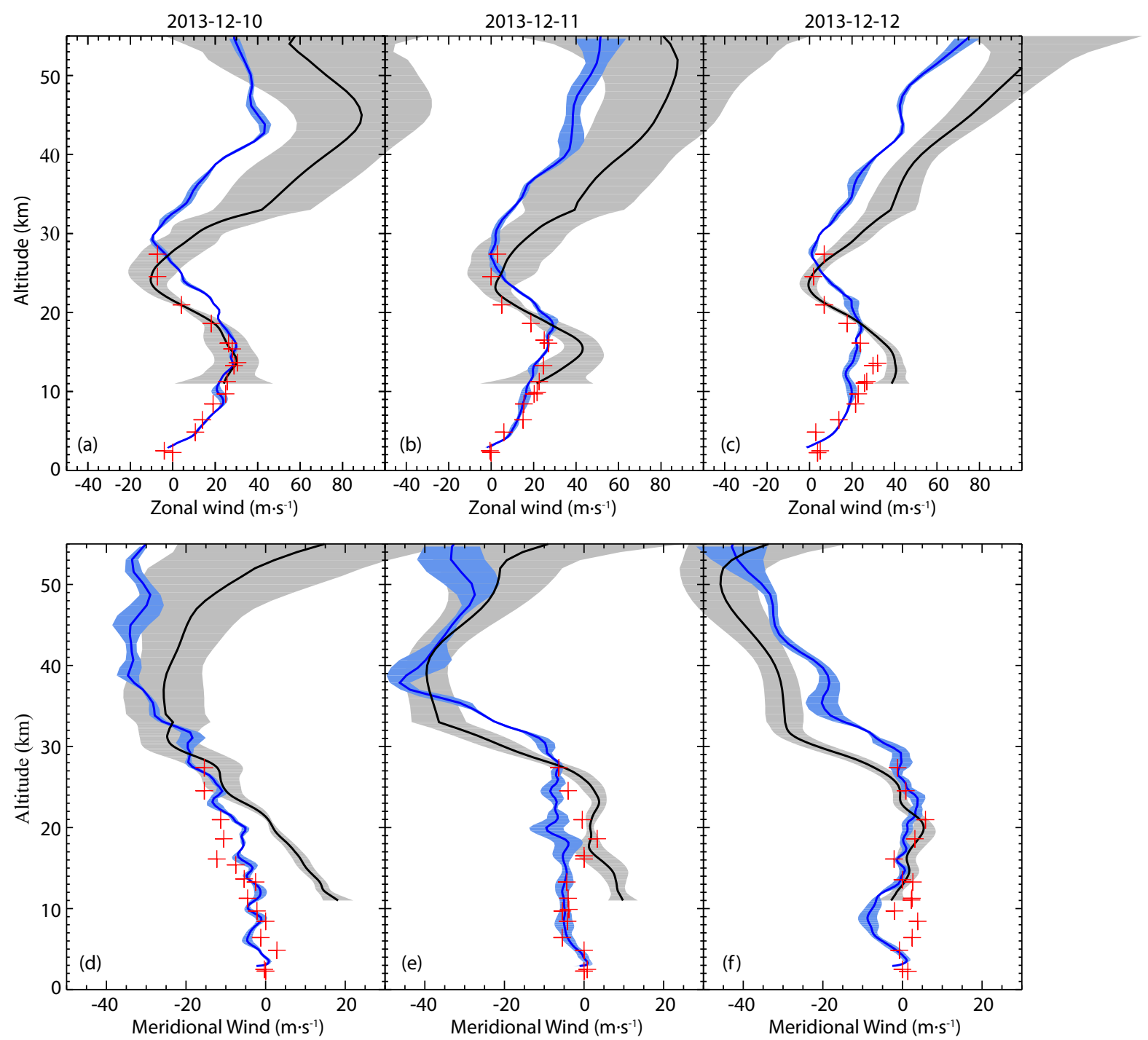

Figure 2. Comparison of daily mean zonal and meridional winds observed by the USTC Doppler wind LiDAR (black curves), ERA5 (blue curves), and radiosondes (red plus symbols) on December $10(a, d), 11(b, e), 12(c, f), 2013$. Shaded ranges indicate standard deviations.

ber 2013 (5.3 hours of measurement time), 11 December 2013 (12 hours), and 12 December 2013 ( 9 hours) obtained by the LiDAR, the ERA5 reanalysis, and from balloon soundings. The balloon sounding data were taken at the meteorological station at Golmud $\left(36.4^{\circ} \mathrm{N}, 94.9^{\circ} \mathrm{E}\right.$, see Figure 1$)$ in Qinghai, which is approximately $240 \mathrm{~km}$ from Delingha. The ERA5 data have been averaged daily over Delingha. Similar to previous studies, the zonal and meridional winds obtained by the LiDAR were consistent with the ERA5 reanalysis below $\sim 30-35 \mathrm{~km}$, and also agreed with the balloon soundings. Discrepancies between the LiDAR observations and the reanalysis data became larger above $35 \mathrm{~km}$ (also below $30 \mathrm{~km}$ in meridional wind on 10 December 2013, see Figure $2 \mathrm{~d}$ ). Such wind biases in the upper stratosphere between LiDAR and reanalysis data have been reported previously (e.g., Xia HY et al., 2012; Dou XK et al., 2014).

Figure 3 shows the hourly zonal and meridional wind observations over Delingha $\left(37.4^{\circ} \mathrm{N}, 97.4^{\circ} \mathrm{E}\right)$ on the night of 11 December. In the upper troposphere and lower stratosphere, i.e., $\sim 10-20 \mathrm{~km}$, the eastward zonal jet was dominant and sustained. A maximum wind speed of $60 \mathrm{~m} / \mathrm{s}$ occurred at approximate 10:20 UT (beginning of the LiDAR observation) and lasted more than one hour on the night of 11 December. In the stratosphere, the zonal wind significantly increased with altitude, with a vertical gradient of up to $\sim 3-4 \mathrm{~m} / \mathrm{s} / \mathrm{km}$ at 30-50 km, whereas the meridional wind was mainly southward, with a maximum of about $-40 \mathrm{~m} / \mathrm{s}$ at approximately $40 \mathrm{~km}$ altitude.

For comparison, Figure 4 shows the ERA5 reanalysis data over Delingha for the night of 11 December. In general, the LiDAR observations and the ERA5 data are in agreement, i.e., the eastward jet in the upper troposphere, the transition from weak easterlies to weak westerlies around 20-30 km altitude, and the southward maximum of the meridional winds in stratosphere. However, the wind strength in the upper stratosphere obtained by the LiDAR was much larger than that in the reanalysis data, especially for the zonal wind. Also shown in Figure 4 is the temperature within the altitude range of the LiDAR observations, which is used to obtain 

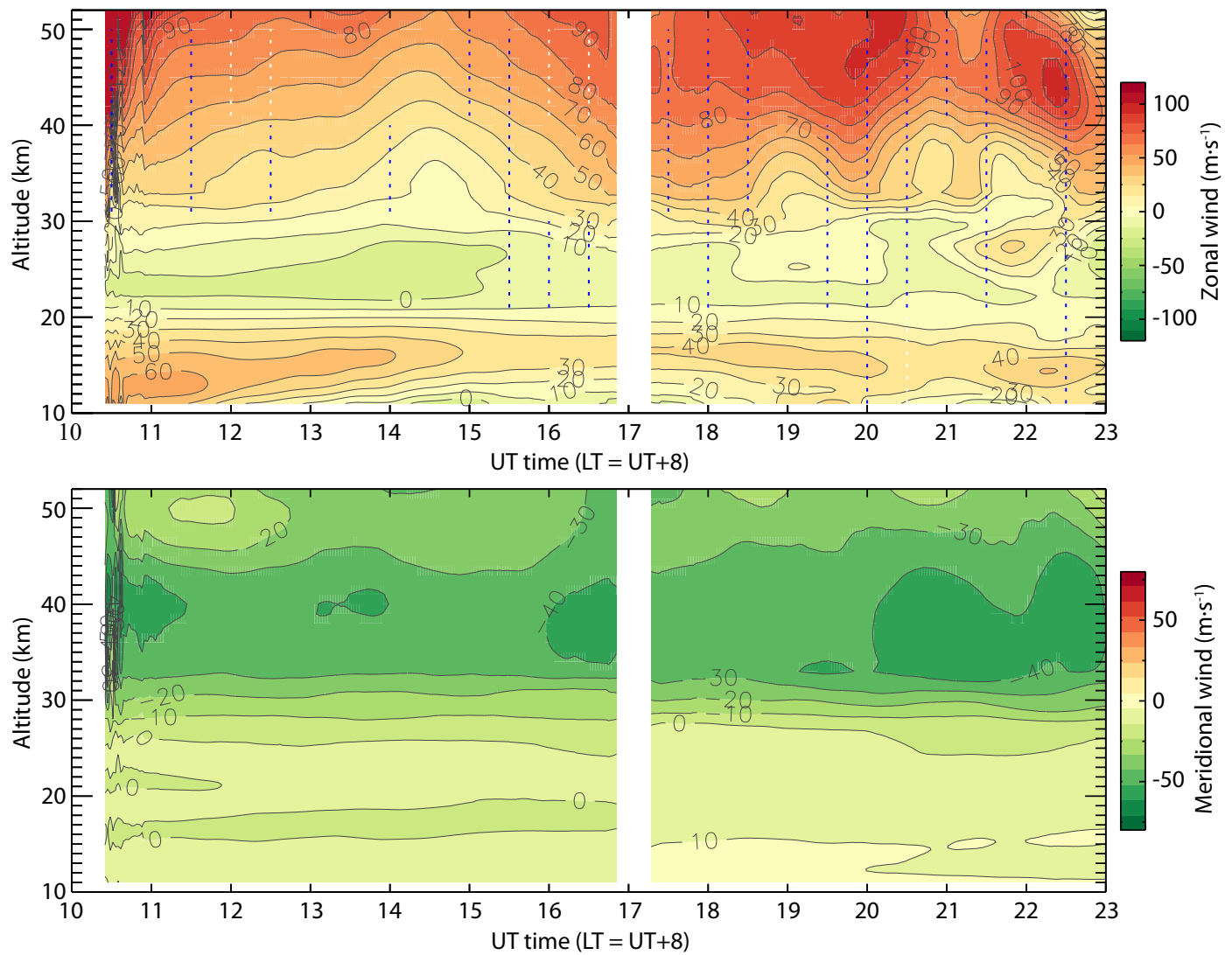

Figure 3. Zonal (top) and meridional (bottom) winds observed by the USTC Doppler wind LiDAR during the night of 11 December 2013 . The blue dotted lines indicate regions with anticlockwise rotation of $u^{\prime}$ and $v^{\prime}$; white dotted lines indicate regions where the rotation direction of $u^{\prime}$ and $v^{\prime}$ can not be determined.

the buoyancy frequency and scale height in the following section.

\section{Gravity Wave Observations by the USTC Doppler Wind LiDAR}

For the gravity wave analysis of the USTC lidar data, wind perturbations were extracted first by subtracting background signals from each wind profile. The background winds were obtained using fourth-order polynomial fits over shifting windows with 20-km width and 1-km steps in altitude. The residual wind perturbations were then filtered through a Butterworth bandpass filter with cutoff frequencies at vertical wavelengths of 7 and $20 \mathrm{~km}$. The gravity wave structures seen in the wind perturbations on 10 and 12 December 2013 (not shown) are quite similar to those reported previously (Zhao RC et al., 2016, 2017). The specific gravity waves signals in the wind perturbations on 11 December were of greater interest. Thus, our investigations focused on $\sim 12$ hours of gravity wave observations on the night of 11 December 2013.

The zonal $\left(u^{\prime}\right)$ and meridional $\left(v^{\prime}\right)$ wind perturbations that occurred from 10:20-22:30 UT on 11 December 2013 are shown in Figure 5. Before 17:00 UT, the gravity waves in $u^{\prime}$ and $v^{\prime}$ exhibited quasi-stationary structures, with maximum amplitudes of $10 \mathrm{~m} / \mathrm{s}$ and $5 \mathrm{~m} / \mathrm{s}$ for $u^{\prime}$ and $v^{\prime}$, respectively. The wavenumber spectra of $u^{\prime}$ (Figure 6) and $v^{\prime}$ (not shown) indicate that the dominant vertical wavelength was $\sim 9-11 \mathrm{~km}$ during this time period. However, small-scale wave modulation was also evident during this period.
After 17:00 UT, the zonal and meridional wind perturbation amplitudes both increased, especially for $u^{\prime}$, which reached a maximum value of $15 \mathrm{~m} / \mathrm{s}$. At the same time, the presence of multiple waves, likely to have been related to downward and upward propagation, became evident in the zonal wind perturbations. The dominant vertical wavelengths in the wavenumber spectra of $u^{\prime}$ and $v^{\prime}$ were not affected significantly after 17:00 UT; i.e., they remained at $\sim 9-11 \mathrm{~km}$.

According to linear gravity wave theory, in-phase wind perturbation $\left(u_{l}\right)$ and quadrature-phase wind perturbation $\left(u_{r^{\prime}}\right)$ amplitudes are related through (Gavrilov et al., 1996; Hu X et al., 2002)

$$
u_{r}^{\prime}=-\mathrm{i} \frac{f}{\hat{\omega}} u_{l}^{\prime},
$$

where $\widehat{\omega}$ is the intrinsic frequency of the wave and $f$ is the Coriolis parameter, which at Delingha corresponds to an inertial period of 19.7 hours. In the northern hemisphere, where $f>0,\left(u_{1}^{\prime}, u_{r}^{\prime}\right)$ will rotate clockwise with altitude if the wave energy propagates upward, and the vector of zonal and meridional wind perturbation follows an ellipse-like rotation with increasing altitude. Using the method of Gavrilov et al. (1996) and Hu X et al. (2002), an ellipse can be fitted to the data. The ratio of the semi-major to the semiminor axis of the ellipse equals the ratio of the intrinsic frequency $\widehat{\omega}$ to the Coriolis parameter $f$, and the orientation of the major axis indicates the horizontal direction in which the wave propagates $\left( \pm 180^{\circ}\right)$. 

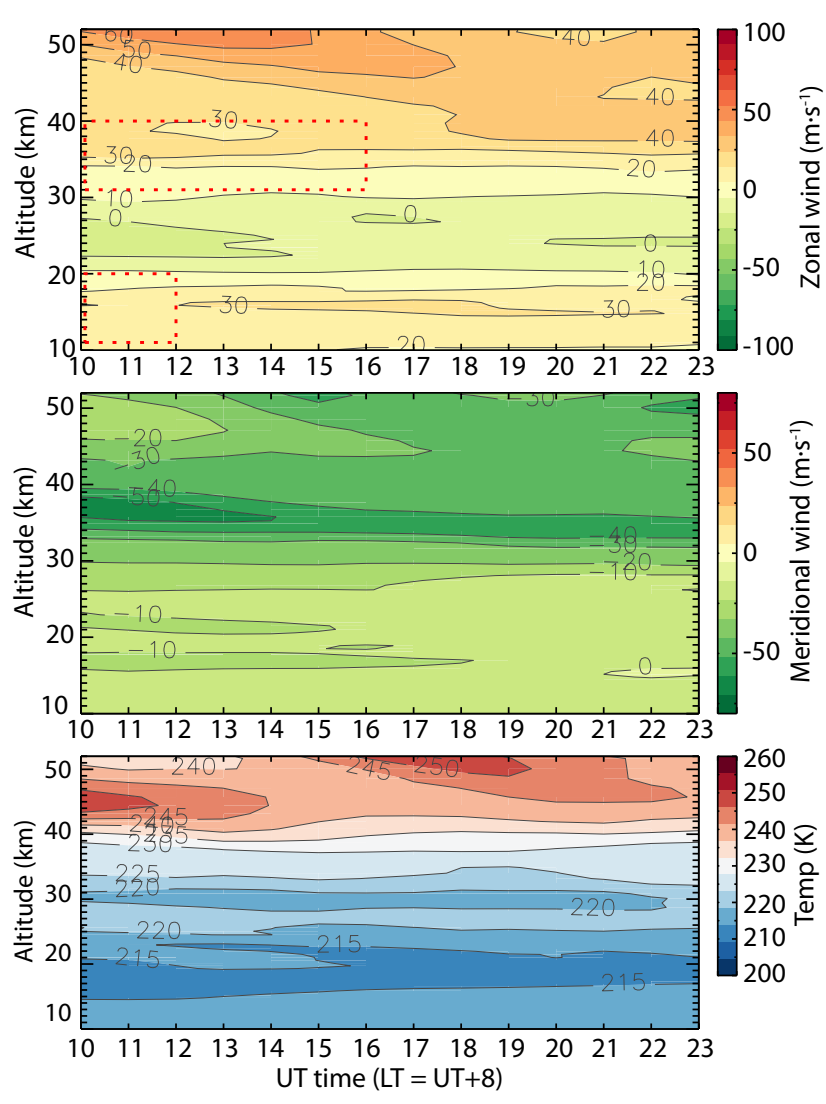

Figure 4. Zonal (top) and meridional (middle) winds as well as temperatures (bottom) obtained from ERA5 hourly reanalysis data during the LiDAR observational period. Red dashed boxes indicate regions with anticlockwise rotation of the ERA5 wind perturbations.

The hodograph analysis was conducted every half hour for altitude intervals of $10 \mathrm{~km}$ (considering that the dominant vertical wavelength was $\sim 10 \mathrm{~km}$ ) using the zonal and meridional wind perturbation profiles from the LiDAR. As an example, Figure 7 shows the hodographs at 11:30 ((a) - (d)) and 17:30 UT ((e) - (h)) for altitudes of $11-20 \mathrm{~km}, 21-30 \mathrm{~km}, 31-40 \mathrm{~km}$, and 41-50 km, respectively. In the altitude range of 11-30 km the hodographs rotated clockwise, which indicates a wave with upward energy propagation $(m<0)$. In contrast, in the altitude range of $31-50 \mathrm{~km}$, the hodographs rotated anticlockwise, which indicates a wave with downward energy propagation $(m>0)$. The major axes of the ellipses fitted within the altitude ranges of $21-30 \mathrm{~km}, 31-40 \mathrm{~km}$, and $41-50 \mathrm{~km}$ were oriented northeast-southwest and tended to be perpendicular to the background wind. The orientation of the ellipses fitted within the altitude range of $11-20 \mathrm{~km}$ was parallel to the background wind. The ratios of the semi-major to semiminor axis at 11:30 and 17:30 for the four altitude regions are listed in Table 2. The data were used to calculate the intrinsic period according to Equation (1).

Assuming a dominant vertical wavelength of $10 \mathrm{~km}$ (Figure 6), the horizontal wavenumber of the gravity waves can be calculated through the dispersion relation,

$$
k^{2}=\frac{\widehat{\omega}^{2}-f^{2}}{N^{2}-\widehat{\omega}^{2}} \cdot\left(m^{2}+\frac{1}{4 H^{2}}\right),
$$

where $k$ and $m$ are the horizontal and vertical wavenumber, respectively. $N$ is the buoyancy frequency, and $H$ is the scale height. As buoyancy frequency and scale height depend on temperature, hourly ERA5 temperature data were interpolated to the corresponding time and altitude of the LiDAR observation. Then the buoyancy frequency and the scale height were calculated through $N^{2}=\frac{g}{T} \cdot\left(\frac{\partial T}{\partial z}+\frac{g}{c_{p}}\right)$ and $H=R T / g$, respectively. Here, $g$ is the gravitational acceleration, $R=287 \mathrm{~J} \cdot \mathrm{K}^{-1} \cdot \mathrm{kg}^{-1}$ is the gas constant for dry air, and $c_{p}=1003.5 \mathrm{~J} \cdot \mathrm{K}^{-1} \cdot \mathrm{kg}^{-1}$ is the specific heat capacity. Thus, the horizontal wavelength was determined by Equation (2) and listed in Table 2.

The statistics of the results of the hodograph analysis at each altitude over time are listed in Table 3. In general, waves with upward energy propagation (clockwise rotation) were dominant from $11-30 \mathrm{~km}$, especially in the range $11-20 \mathrm{~km}$. At the lowest heights, $\sim 91 \%$ of profiles exhibit clockwise rotation. Waves with downward energy propagation (anticlockwise rotation) were dominant at upper altitudes, i.e., the fraction was $54 \%$ and $60 \%$ at 31-40 km and 41-50 km, respectively. Regions with anticlockwise rotation of $u^{\prime}$ and $v^{\prime}$ are indicated by blue dotted lines in Figure $3 a$. After 15:00 UT, when strong zonal wind amplitudes appeared above $35 \mathrm{~km}$, the fraction of waves with downward energy propagation (anticlockwise rotation) increased to $\sim 60 \%$ and $77 \%$ at $31-40 \mathrm{~km}$ and $41-50 \mathrm{~km}$, respectively. The orientations of the fitted ellipse major axis, which are listed in Table 3, indicate that the waves at different altitude regions favored different propagation directions (considering the $\pm 180^{\circ}$ uncertainty). For example, the median value of the orientation angle in the altitude region of $11-20 \mathrm{~km}$ was $153^{\circ}$ (clockwise from east), while the median value in the altitude range of $41-50 \mathrm{~km}$ was $38^{\circ}$. These statistical results suggest that the waves were related to different sources.

Simultaneous upward and downward propagating inertia-gravity waves in the mesosphere and lower thermosphere region have been reported previously (Huang XM et al., 2017) with the suggestion that the upward and downward waves are generated by different sources, i.e., the stratospheric jet adjustment and reflection in the realistic atmospheric wind field. In the following section, we will further discuss possible sources of the waves observed above.

\section{Possible Wave Sources}

\subsection{Waves in the Middle and Upper Stratospheric Region of $\mathbf{3 0 - 5 0 ~} \mathrm{km}$}

The same method used to extract wind perturbations from the LiDAR data was used to obtain $u^{\prime}$ and $v^{\prime}$ from the ERA5 hourly wind data (not shown). Initially, the waves seen in the wind perturbations were the same as those in Figure 5. However, the complex structures in the zonal wind perturbations after 17:00 UT did not appear in the ERA5 data. The hodograph analysis also was conducted every hour using ERA5 $u^{\prime}$ and $v^{\prime}$ data in 10-km altitude intervals. In general, clockwise rotation was dominant. Regions with anticlockwise rotation of $u^{\prime}$ and $v^{\prime}$ are indicated in Figure 4. Inconsistencies in the hodograph analyses between the LiDAR and ERA5 data appeared mainly above $40 \mathrm{~km}$, where anticlockwise rotation was dominant only in the LiDAR data. 

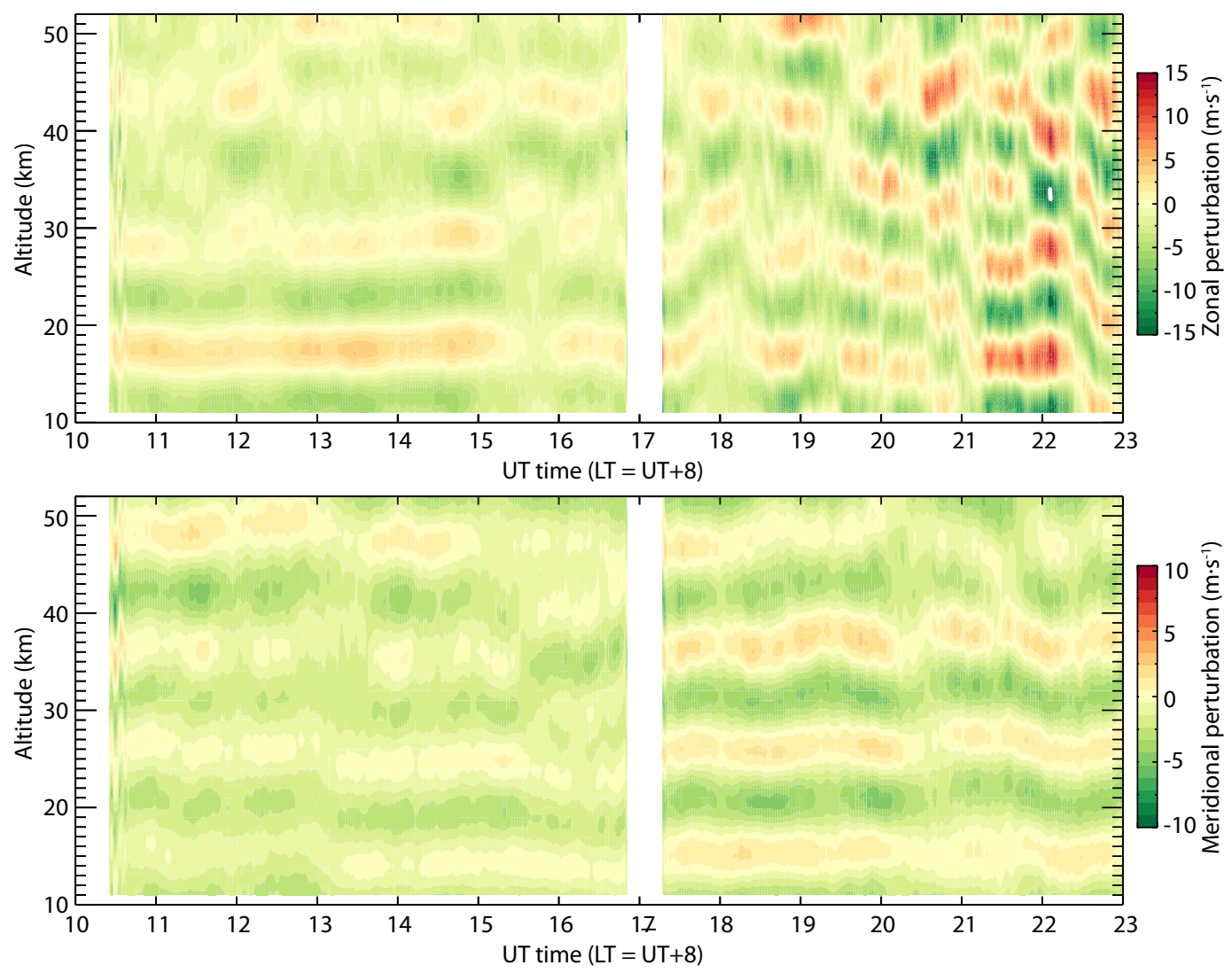

Figure 5. Zonal (top) and meridional (bottom) wind perturbations extracted from USTC Doppler wind LiDAR observations on 11 December 2013.

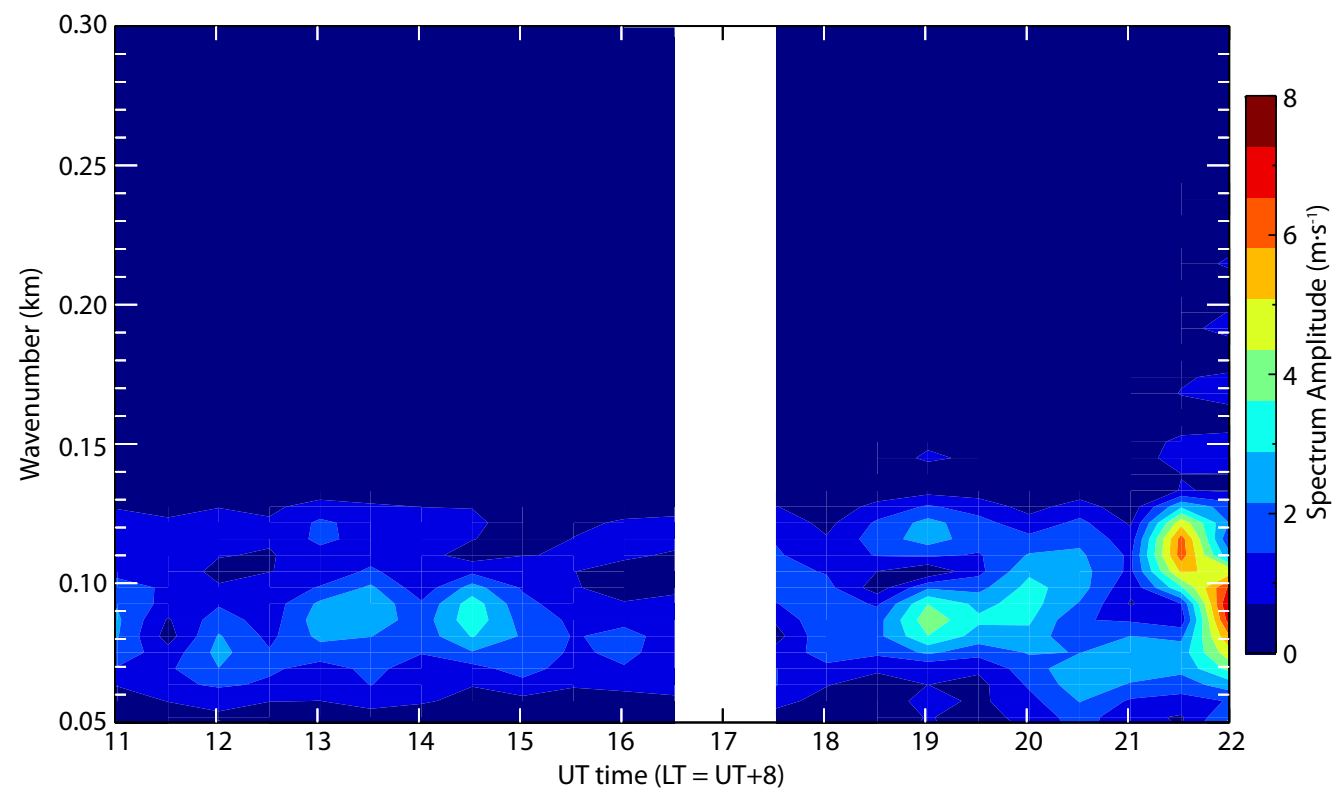

Figure 6. Lomb-Scargle periodogram to estimate vertical wavelengths from the zonal wind perturbation.

One reason for the differences between the LiDAR and ERA5 data is that the enhancement of the zonal winds at upper levels after 15:00 UT was not reproduced in the ERA5 reanalysis data. The wind amplitude above $35 \mathrm{~km}$ was underestimated in the ERA5 data, and the strong zonal wind $(50 \mathrm{~m} / \mathrm{s})$ and meridional wind
( -40 m/s) existed only in the ERA5 data from 10:00-16:00 UT above $35 \mathrm{~km}$ (Figure 4). For more detail, another indicator of gravity wave activity, the horizontal wind divergences, were investigated for 12:00 UT (i.e., the strong upper zonal wind period in the ERA5 data). Figure 8 a shows a west-east cross-section for the 

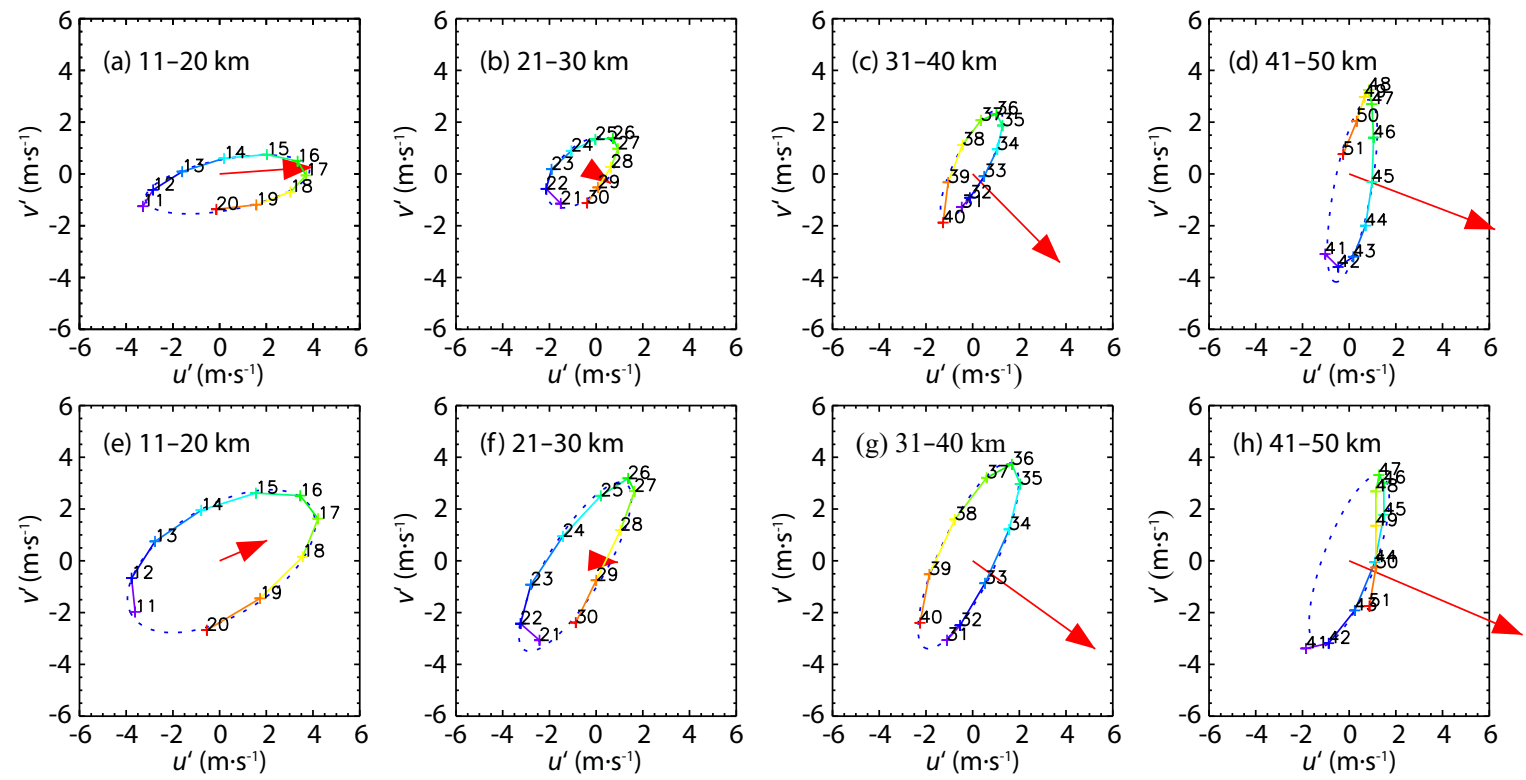

Figure 7. Hodographs of zonal and meridional wind perturbations observed by the USTC Doppler wind LiDAR at 11:30 UT (top) and 17:30 UT (bottom) within the altitude ranges of 11-20 km (a, e), 21-30 km (b, f), 31-40 km (c, g), and 41-50 km (d, h). Color coding ranging from blue to red indicates increasing altitude. Blue dashed lines are ellipses fitted to the hodographs. Red arrows show background wind speed and direction within the altitude ranges, with wind speed being divided by a factor of 10 .

Table 2. Hodograph analysis of $u^{\prime}$ and $v^{\prime}$ observed by the USTC LiDAR on 11 December 2013 at 11:30 and 17:30 UT.

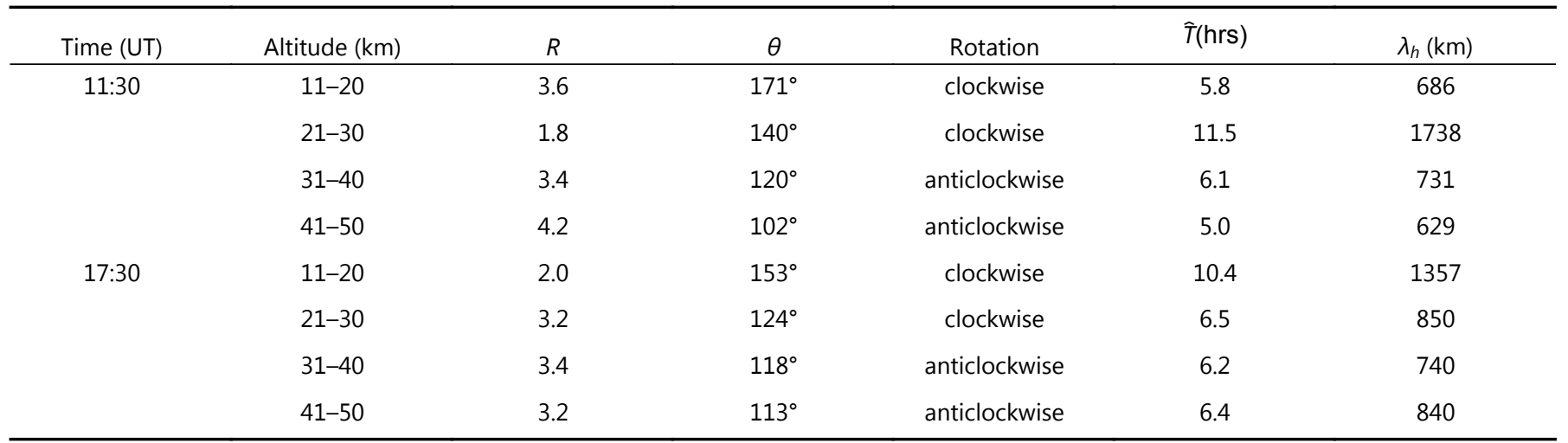

$R$ is ratio of hodograph ellipse semi-major axis to semi-minor axis; $\theta$ is orientation angle of the ellipse (clockwise from east); $T$ is intrinsic period.

Table 3. Statistics of the hodograph analysis for the full observation period on 11 December 2013

\begin{tabular}{|c|c|c|c|c|c|c|c|}
\hline Altitude (km) & \multicolumn{3}{|c|}{$R$} & \multicolumn{3}{|c|}{$\theta$} & clockwise (\%) \\
\hline $11-20$ & 3.8 & 4.2 & 1.8 & $153^{\circ}$ & $100^{\circ}$ & $72^{\circ}$ & 91 \\
\hline $21-30$ & 3.4 & 3.7 & 1.9 & $136^{\circ}$ & $103^{\circ}$ & $66^{\circ}$ & 63 \\
\hline $31-40$ & 3.4 & 3.9 & 2.5 & $64^{\circ}$ & $73^{\circ}$ & $63^{\circ}$ & 46 \\
\hline
\end{tabular}

$R$ is ratio of hodograph ellipse semi-major axis to semi-minor axis; $\theta$ is orientation angle of the ellipse (clockwise from east); clockwise is fraction of hodograph profiles with clockwise rotation.

ERA5 horizontal wind divergence along the latitude of Delingha (i.e., $37.4^{\circ} \mathrm{N}$ ) from $25-55 \mathrm{~km}$ altitude. Waves with vertical wavelengths of $\sim 10-15 \mathrm{~km}$ were present over Delingha. At 12:00 UT, a strong wind jet at $\sim 36-38 \mathrm{~km}$ existed over Delingha $\left(97.4^{\circ} \mathrm{E}\right.$, the vertical black line). Below the jet (positive wind shear region), the wave patterns slanted toward the east. Above the jet (negat- ive wind shear region), the wave patterns slanted toward the west. The divergence on the longitude-latitude plane at $\sim 37 \mathrm{~km}$, the jet maximum altitude, is shown in Figure $8 \mathrm{~b}$. The wind blew from northwest to southeast and formed a tongue-shaped jet. Consecutive plots of the horizontal wind divergence indicate that the wave propagated against the background wind, i.e., toward 


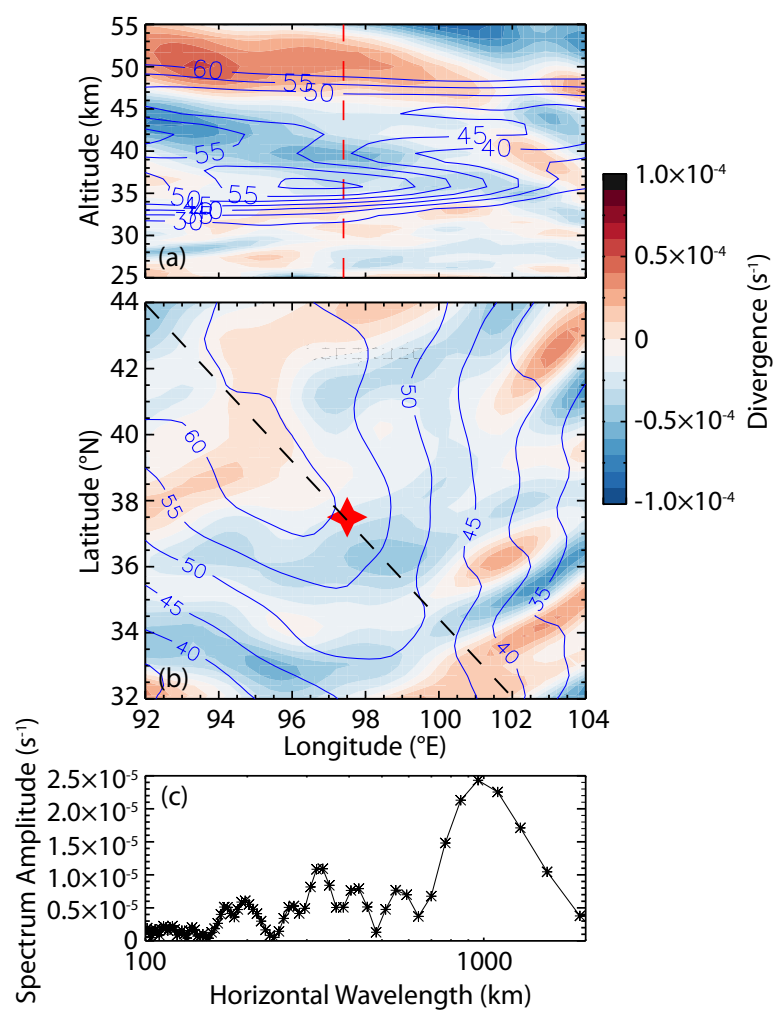

Figure 8. Wind divergence obtained from ERA5 reanalysis data on 11 December 2013, 12:00 UT. (a) West-east cross-section of the horizontal wind divergence along the latitude of Delingha $\left(37.4^{\circ}\right)$ at 25-55 km altitude. Wind speed is plotted with blue contours; Delingha is indicated by the red dashed line. (b) Longitude-latitude plane at $\sim 37 \mathrm{~km}$ (the jet maximum altitude) showing wind divergence as well as wind speed. Delingha is indicated by a red star; the wave propagating direction is indicated by the black dashed line. (c) Lomb-Scargle periodogram along the dashed line across Delingha shown in (b).

the northwest. For a westward propagating wave, an east-slanted wave pattern below the jet in the longitude-height cross-section (Figure 8a) indicates a wave with downward energy propagation $(m>0)$, and a west-slanted wave pattern above the jet in Figure $8 \mathrm{a}$ indicates a wave with upward energy propagation $(m<0)$. The propagation of the waves agrees with the hodograph analysis of the ERA5 wind data at this period, suggesting that the wave with downward energy propagation (anticlockwise rotation) from 10:00-16:00 UT within the 30-40 km range was related to the jet at $36-38 \mathrm{~km}$. Over Delingha, the dominant horizontal wavelength along the wave propagating direction (black line) was $900-1000 \mathrm{~km}$, which is shown in Figure 8c.

The ERA5 wind perturbations within the range of $30-40 \mathrm{~km}$ from 10:00-16:00 UT were similar to the LiDAR wind perturbations within the $30-50 \mathrm{~km}$ range. The main difference is that the strong jet $(50 \mathrm{~m} / \mathrm{s})$ with a large positive wind shear covered the altitude region above $35 \mathrm{~km}$ for nearly the entire observational period and only deaccelerated from 10:00-14:00 UT. Thus, the enhancement of the jet might have contributed greatly to wave formation with downward energy propagation and resulted in anticlockwise rotation in the LiDAR hodograph within the $30-50 \mathrm{~km}$ range, which is shown in Figure 3a and 7. As mentioned in the previous section, the enhancement of the fractions of waves with downward energy propagation (anticlockwise rotation) within the altitude range of $30-50 \mathrm{~km}$ after 15:00 UT, is likely to have been related to the existence of the jet. Both the median and average orientation angles of the hodograph ellipses were less than $90^{\circ}$, which indicates that the waves propagated along the northwest-southeast direction. This is consistent with the wave direction revealed by the ERA5 wind divergence, which is shown in Figure 8b, i.e., toward the northwest. The corresponding horizontal wavelengths, i.e., $600-800 \mathrm{~km}$ for the wave within the $31-50 \mathrm{~km}$ range at 11:30 UT (Table 2), were also close to that of the ERA5 data at $\sim 37 \mathrm{~km}$, i.e., $900-1000 \mathrm{~km}$, which is shown in Figure 8c. In fact, the horizontal wind divergence of the ERA5 data indicates that the waves tended to propagate to the northwest above $\sim 25 \mathrm{~km}$ with dominant horizontal wavelengths of $\sim 800-1000 \mathrm{~km}$, which is similar to the wave structures mentioned above.

\subsection{Waves in Lower Stratosphere and Upper Troposphere Region of 10-30 km}

Away from the upper jet, the gravity waves at lower altitudes showed a preference for propagating downward (upward energy propagation). Convection is an important tropospheric source of gravity waves. However, LiDARs are usually operated during clear nights only, and thus no local convective system is likely to have occurred over Delingha during the night of 11 December 2013.

Figure 9a shows the total effective cloud fraction (0-1.0) assuming unit cloud top emissivity observed by the Atmospheric Infrared Sounder (AIRS) aboard NASA's Aqua satellite on 11 December 2013 at 19:35 UT over Delingha. The histogram and the cumulative probability of the simultaneous AIRS observation of the cloud top temperature are shown in Figure 9b, which indicates that most measurements (99.4\%) of the cloud top temperature were higher than $210 \mathrm{~K}$, which is considered a threshold for detection of deep convective clouds (Aumann et al., 2006). Thus, no evident features of deep convective cloud in the latitude region of $35^{\circ} \mathrm{N}$ to $41^{\circ} \mathrm{N}$ and the longitude region of $88^{\circ} \mathrm{E}$ to $106^{\circ} \mathrm{E}$ were detected, and we may rule out convection as a source of the upward propagating gravity waves at lower heights.

Several studies have focused on inertial gravity waves generated by lower stratospheric jets. Vaughan and Worthington (2007) found that, in the lower stratosphere, clockwise rotation of inertial gravity waves is dominant, with upward energy propagation associated with jet-stream, and that inertial gravity wave activity increases when the jet speed increases. In our case study, the jets in the lower stratosphere were observed by LiDAR and were also captured by the ERA5 data. However, the jet strength was approximately 2 times stronger in the LiDAR observation ( 50-60 m/s) than in the ERA5 data $(\sim 30 \mathrm{~m} / \mathrm{s})$. Figure 10a shows a longitude-latitude plane at $\sim 13 \mathrm{~km}$ (i.e., the altitude of the lower jet). Different from the upper altitude region, the wavefront was oriented along the northeast-southwest direction. The median and average value of orientation angles of the hodograph ellipses were larger than $90^{\circ}$ (Table 3) at lower altitudes, which is consistent with the wave pattern shown in Figure 10a. The horizontal wavelength along the wave propagation direction (black line in 

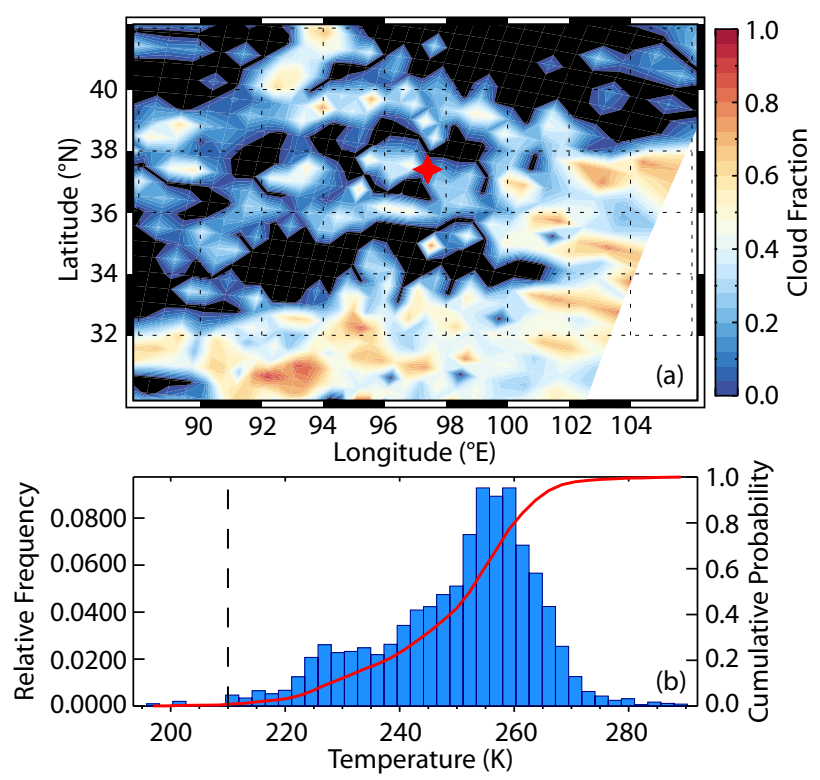

Figure 9. AIRS observations at 19:35 UT on 11 December 2013. (a) The total effective cloud fraction (0-1) assuming unit cloud top emissivity; the location of Delingha is indicated by the star symbol. (b) The histogram and the cumulative probability of the simultaneous AIRS observation of the cloud top temperature; the black dashed line indicates a cloud top temperature of $210 \mathrm{~K}$.

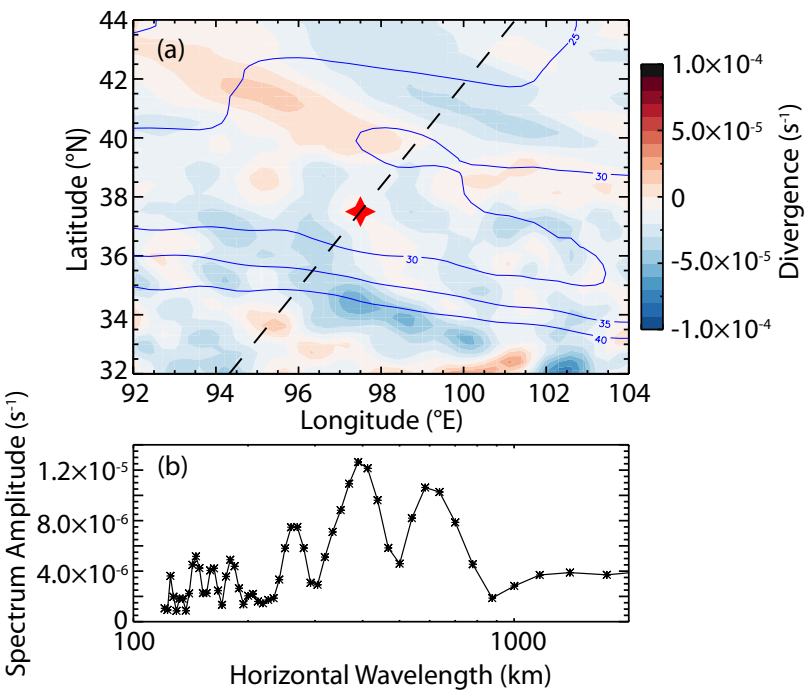

Figure 10. Analysis of wind divergences obtained from ERA5 reanalysis data on 11 December 2013, 12:00 UT. (a) Longitude-latitude plane at $\sim 13 \mathrm{~km}$ (the lower jet maximum altitude). Wind speeds are indicated by blue contour lines. Delingha is indicated by the red star symbol. (b) Lomb-Scargle periodogram along the dashed line across Delingha shown in (a).

Figure 10a) was estimated as $400-700 \mathrm{~km}$, which agrees with the horizontal wavelength obtained from the LiDAR hodograph listed in Table 2.

Figure 11 shows the synoptic scale potential vorticity $(\mathrm{PV})$ at the $370 \mathrm{~K}$ isentropic surface $(\sim 12-13 \mathrm{~km})$ as well as the wind and its horizontal divergence. The wind flow followed the high-PV curvature, and the high-PV air propagated eastward. Delingha is in the vicinity of an inflexion region of the jet-stream's curved structure. The flow became unbalanced in the region and inertial gravity waves were generated, which is shown in Figure 11. The situation is quite similar to numerical simulations performed by O'Sullivan and Dunkerton (1995), and to the observations of Plougonven and Teitelbaum (2003). Numerical simulations have indicated that quasi-stationary gravity waves with vertical wavelengths from $\sim 5-15 \mathrm{~km}$ and horizontal wavelengths of tens to hundreds of kilometers can be generated in association with such a jet front (Kim et al., 2016). Thus the dominant clockwise rotation in the hodograph in the lower altitude region, which is shown in Figure 7, is likely to have been related to the jet within the $10-15 \mathrm{~km}$ region.

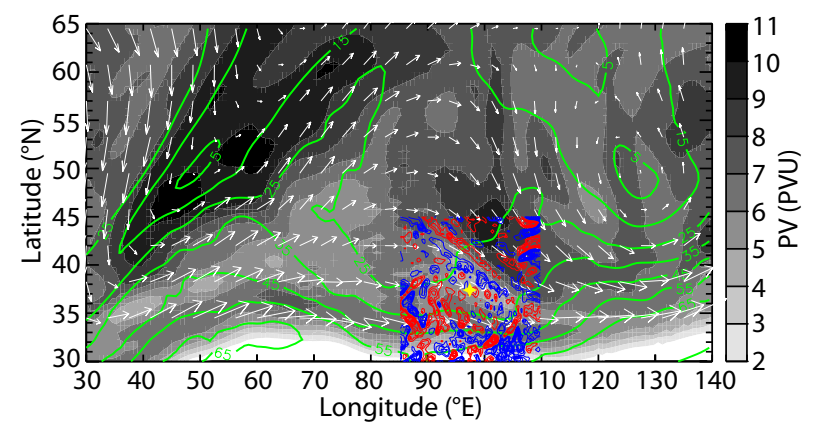

Figure 11. ERA5 synoptic-scale potential vorticity on the $370 \mathrm{~K}$ isentropic surface ( 12-13 km) on 11 December 2013, 12:00 UT. Wind amplitude is indicated by the green line; wind direction is marked by white arrows. Wind divergences around Delingha (yellow star) are indicated by red (positive) and blue (negative) contour lines.

Delingha is located northeast of the Qinghai-Tibet Plateau. Figure 12 shows a west-east cross-section of the topography along the latitude of Delingha (i.e., $37.4^{\circ} \mathrm{N}$ ) as well as ERA5 vertical winds between $0-20 \mathrm{~km}$ at 12:00 UT. Although there were some mountain wave-like vertical wind perturbations below $10 \mathrm{~km}$, the vertical wind velocities in this region were very smaller (much less than $0.1 \mathrm{~m} / \mathrm{s}$ ). Spiga et al. (2008) claimed that mountain waves have significant vertical wind velocities of $\sim 1 \mathrm{~m} / \mathrm{s}$ or more. Vaughan and Worthington (2007) used a threshold for vertical wind velocity of $0.15 \mathrm{~m} / \mathrm{s}$ to identify mountain wave events. Furthermore, the potential temperature contours shown in Figure 12 do not show the structure of folding or deformation related to topography, which is usually the case when mountain waves are present. Also, Figure 3 indicates that zonal and meridional mean wind reversals occurred at 20-30 km on 11 December at 10:20- 15:00 UT and during the entire observational period, respectively. The wind reversal did not favor the vertical propagation of orographic gravity waves.

\section{Conclusions}

In this paper, we focus on inertial gravity waves observed by the USTC Doppler wind LiDAR over Delingha $\left(37.4^{\circ} \mathrm{N}, 97.4^{\circ} \mathrm{E}\right)$ during the night of 11 December 2013. The waves appeared to be stationary with vertical wavelengths of 9-11 km. A hodograph analysis indicates that characteristics of the inertial gravity waves 


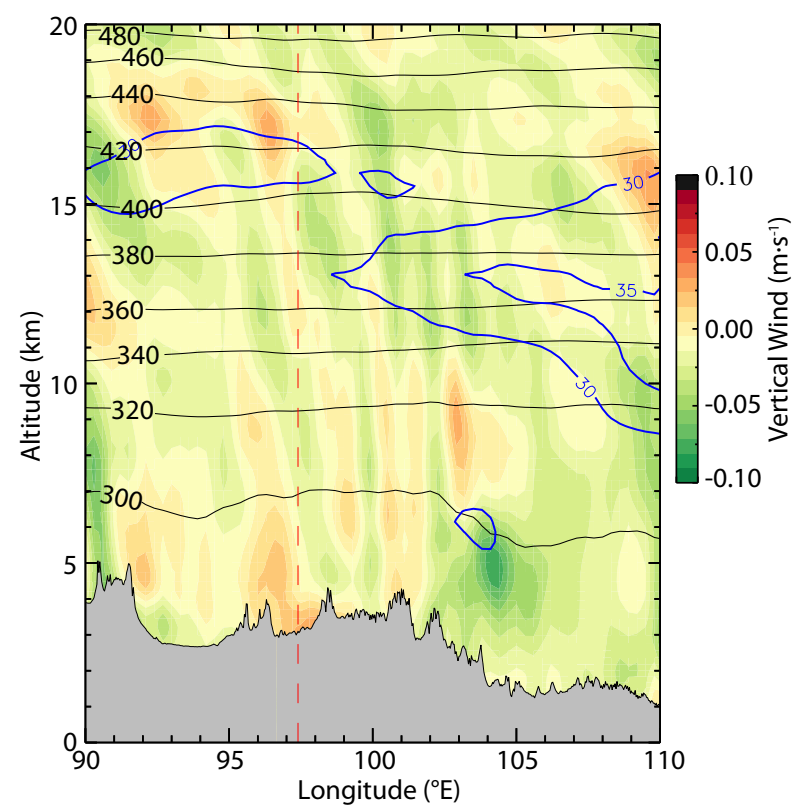

Figure 12. West-east cross-section of topography and ERA5 vertical winds between 0-20 km on 11 December 2013, 12:00 UT along the latitude of Delingha $\left(37.4^{\circ} \mathrm{N}\right)$. Wind amplitudes larger than $30 \mathrm{~m} / \mathrm{s}$ are contoured with blue lines.

differed in the lower and upper stratosphere. At upper altitudes ( 30-50 km), downward propagation was dominant, especially during a period of enhanced zonal wind speeds. At lower altitudes ( 10-20 km), upward propagation of the waves was dominant. The averaged horizontal wave propagation directions were northwest-southeast and northeast-southwest at the upper and lower altitudes, respectively. This analysis suggests that upper and lower level gravity waves have different sources.

Combining ERA5 reanalysis data with the LiDAR data reveals the existence of large-scale waves with horizontal wavelengths of $800-1000 \mathrm{~km}$ in the altitude range of $30-50 \mathrm{~km}$ over Delingha on the night of 11 December 2013. The wavefront was tilted along the northeast-southwest direction and propagated toward the northwest against the background wind. This is consistent with the wave features obtained by LiDAR hodograph analysis in the range of 30-50 km, i.e., propagation along the northwest-southeast direction and a horizontal wavelength of $\sim 900 \mathrm{~km}$.

In this case study, we conclude that the waves with downward energy propagation within the $30-50 \mathrm{~km}$ altitude range were generated by the upper level wind jet observed by the LiDAR, which was much stronger than that shown by the ERA5 reanalysis. Based on our current analysis, we conclude that the waves with upward energy propagation in the lower altitude region, i.e., $\sim 10-20 \mathrm{~km}$, are likely to have been generated by the lower stratospheric jet observed by the LiDAR. The ERA5 reanalysis shows that the wavefront tilted along the northwest-southeast direction and propagated along the northeast direction with a dominant horizontal wavelength range of $400-700 \mathrm{~km}$, which again indicates the wave features observed by LiDAR at lower altitudes. Thus we conclude that the inertial gravity waves observed by the LiDAR were generated by different sources, in this case related to the upper and lower jets.

\section{Acknowledgments}

We would like to thank Dr. Lars Hoffmann for his great help in reviewing this manuscript. We acknowledge the data used in this paper from the Chinese Meridian Project and the Solar-Terrestrial Environment Research Network (STERN), as well as the ERA5 data from the European Centre for Medium-Range Weather Forecasts, and the AIRS data provided by NASA. The wind LiDAR data and radiosonde are available from University of Science and Technology of China LiDAR group. The ERA5 data can be accessed from https://www.ecmwf.int/. The AIRS Level 2 data are distributed by the NASA Goddard Earth Sciences Data Information and Services Center (AIRS Science Team and Chahine, 2007). This work is supported by the B-type Strategic Priority Program of Chinese Academy of Sciences Grant No. XDB41000000, the National Natural Science Foundation of China (41774158, 41974174, 41831071, and 41904135), the China National Space Administration pre-research Project on Civil Aerospace Technologies No. D020105, and the Open Research Project of Large Research Infrastructures of CAS "Study on the interaction between low/mid-latitude atmosphere and ionosphere based on the Chinese Meridian Project."

\section{References}

AIRS Science Team, and Chahine, M. (2007). AIRS/Aqua L1B Infrared (IR) geolocated and calibrated radiances V005, version 005, Greenbelt, MD, USA, Goddard Earth Sciences Data and Information Services Center (GES DISC). available at http://disc.gsfc.nasa.gov/datacollection/AIRIBRAD_005.html. last access: 31 December 2015.

Alexander, S. P., Klekociuk, A. R., and Murphy, D. J. (2011). Rayleigh LiDAR observations of gravity wave activity in the winter upper stratosphere and lower mesosphere above Davis, Antarctica $\left(69^{\circ} \mathrm{S}, 78^{\circ} \mathrm{E}\right)$. J. Geophys. Res.: Atmos., 116(D13), D13109. https://doi.org/10.1029/2010JD015164

Aumann, H. H., Gregorich, D., and De Souza-Machado, S. M. (2006). AIRS observations of deep convective clouds. In Proceedings Volume 6301, Atmospheric and Environmental Remote Sensing Data Processing and Utilization II: Perspective on Calibration/Validation Initiatives and Strategies. San Diego: SPIE. https://doi.org/10.1117/12.681201

Baumgarten, G., Fiedler, J., Hildebrand, J., and Lübken, F. J. (2015). Inertia gravity wave in the stratosphere and mesosphere observed by Doppler wind and temperature LiDAR. Geophys. Res. Lett., 42(24), 10929-10936. https://doi.org/10.1002/2015GL066991

Chen, C., Chu, X. Z., Zhao, J., Roberts, B. R., Yu, Z. B., Fong, W., Lu, X., and Smith, J. A. (2016). Lidar observations of persistent gravity waves with periods of $3-10 \mathrm{~h}$ in the Antarctic middle and upper atmosphere at McMurdo $\left(77.83^{\circ} \mathrm{S}\right.$, $166.67^{\circ}$ E). J. Geophys. Res. Space Phys., 121(2), 1483-1502. https://doi.org/10.1002/2015JA022127

Dou, X. K., Han, Y. L., Sun, D. S., Xia, H. Y., Shu, Z. F., Zhao, R. C., Shangguan, M. J., and Guo, J. (2014). Mobile Rayleigh Doppler LiDAR for wind and temperature measurements in the stratosphere and lower mesosphere. Opt. Express, 22(S5), A1203-A1221. https://doi.org/10.1364/OE.22.0A1203

Fritts, D. C., and Alexander, M. J. (2003). Gravity wave dynamics and effects in the middle atmosphere. Rev. Geophys., 41(1), 1003. https://doi.org/10.1029/2001RG000106

Gavrilov, N. M., Fukao, S., Nakamura, T., Tsuda, T., Yamanaka, M. D., and Yamamoto, M. (1996). Statistical analysis of gravity waves observed with the middle and upper atmosphere radar in the middle atmosphere: 1. Method and general characteristics. J. Geophys. Res. Atmos., 101(D23), 29511-29521. https://doi.org/10.1029/96JD01447

Guest, F. M., Reeder, M. J., Marks, C. J., and Karoly, D. J. (2000). Inertia-gravity waves observed in the lower stratosphere over Macquarie Island. J. Atmos. 
Sci., 57(5), 737-752. https://doi.org/10.1175/15200469(2000)057<0737:IGWOIT>2.0.CO;2

Hersbach, H., and Dee, D. (2016). ERA5 reanalysis is in production. ECMWF Newsletter, No. 147, ECMWF, Reading, United Kingdom, 7. Available online at https://www.ecmwf.int/en/newsletter/147/news/era5-reanalysisproduction

Hertzog, A., Souprayen, C., and Hauchecorne, A. (2001). Measurements of gravity wave activity in the lower stratosphere by Doppler LiDAR. J. Geophys. Res. Atmos., 106(D8), 7879-7890. https://doi.org/10.1029/2000JD900646

Hu, X., Liu, A. Z., Gardner, C. S., and Swenson, G. R. (2002). Characteristics of quasi-monochromatic gravity waves observed with Na LiDAR in the mesopause region at Starfire Optical Range, NM. Geophys. Res. Lett., 29(24), 22-1. https://doi.org/10.1029/2002GL014975

Huang, K. M., Liu, A. Z., Zhang, S. D., Yi, F., Huang, C. M., Gong, Y., Gan, Q., Zhang, Y. H., and Wang, R. (2017). Simultaneous upward and downward propagating inertia-gravity waves in the MLT observed at Andes Lidar Observatory. J. Geophys. Res. Atmos., 122(5), 2812-2830. https://doi.org/10.1002/2016JD026178

Kaifler, B., Lübken, F. J., Höffner, J., Morris, R. J., and Viehl, T. P. (2015). Lidar observations of gravity wave activity in the middle atmosphere over Davis $\left(69^{\circ} \mathrm{S}, 78^{\circ} \mathrm{E}\right)$, Antarctica. J. Geophys. Res. Atmos., 120(10), 4506-4521. https://doi.org/10.1002/2014JD022879

Kim, Y. H., Chun, H. Y., Park, S. H., Song, I. S., and Choi, H. J. (2016). Characteristics of gravity waves generated in the jet-front system in a baroclinic instability simulation. Atmos. Chem. Phys., 16(8), 4799-4815. https://doi.org/10.5194/acp-16-4799-2016

Kogure, M., Nakamura, T., Ejiri, M. K., Nishiyama, T., Tomikawa, Y., Tsutsumi, M., Suzuki, H., Tsuda, T. T., Kawahara, T. D., and Abo, M. (2017). Rayleigh/Raman LiDAR observations of gravity wave activity from 15 to $70 \mathrm{~km}$ altitude over Syowa $\left(69^{\circ} \mathrm{S}, 40^{\circ} \mathrm{E}\right)$, the Antarctic. J. Geophys. Res. Atmos., 122(15), 7869-7880. https://doi.org/10.1002/2016JD026360

Li, T., Leblanc, T., McDermid, I. S., Wu, D. L., Dou, X. K., and Wang, S. (2010). Seasonal and interannual variability of gravity wave activity revealed by long-term LiDAR observations over Mauna Loa Observatory, Hawaii. J. Geophys. Res. Atmos., 115(D13), D13103. https://doi.org/10.1029/2009JD013586

Liu, A. Z., Lu, X., and Franke, S. J. (2013). Diurnal variation of gravity wave momentum flux and its forcing on the diurnal tide. J. Geophys. Res. Atmos., 118(4), 1668-1678. https://doi.org/10.1029/2012JD018653

Lu, X., Chu, X. Z., Fong, W., Chen, C., Yu, Z. B., Roberts, B. R., and McDonald, A. J. (2015). Vertical evolution of potential energy density and vertical wave number spectrum of Antarctic gravity waves from 35 to $105 \mathrm{~km}$ at McMurdo (77.8 $\left.{ }^{\circ} \mathrm{S}, 166.7^{\circ} \mathrm{E}\right)$. J. Geophys. Res. Atmos., 120(7), 2719-2737. https://doi.org/10.1002/2014JD022751

Lu, X., Chu, X. Z., Li, H. Y., Chen, C., Smith, J. A., and Vadas, S. L. (2017). Statistical characterization of high-to-medium frequency mesoscale gravity waves by LiDAR-measured vertical winds and temperatures in the MLT. J. Atmos. Sol.-
Terr. Phys., 162, 3-15. https://doi.org/10.1016/j.jastp.2016.10.009

McDonald, A. J., Thomas, L., and Wareing, D. P. (1998). Night-to-night changes in the characteristics of gravity waves at stratospheric and lowermesospheric heights. Ann. Geophys., 16(2), 229-237. https://doi.org/10.1007/s00585-998-0229-0

O'Sullivan, D., and Dunkerton, T. J. (1995). Generation of inertia-gravity waves in a simulated life cycle of baroclinic instability. J. Atmos. Sci., 52(21), 3695-3716. https://doi.org/10.1175/15200469(1995)052<3695:GOIWIA>2.0.CO;2

Placke, M., Hoffmann, P., Gerding, M., Becker, E., and Rapp, M. (2013). Testing linear gravity wave theory with simultaneous wind and temperature data from the mesosphere. J. Atmos. Sol. -Terr. Phys., 93, 57-69. https://doi.org/10.1016/j.jastp.2012.11.012

Plougonven, R., and Teitelbaum, H. (2003). Comparison of a large-scale inertiagravity wave as seen in the ECMWF analyses and from radiosondes. Geophys. Res. Let., 30(18), 1954. https://doi.org/10.1029/2003GL017716

Plougonven, R., Teitelbaum, H., and Zeitlin, V. (2003). Inertia gravity wave generation by the tropospheric midlatitude jet as given by the Fronts and Atlantic Storm-Track Experiment radio soundings. J. Geophys. Res. Atmos., 108(D21), 4686. https://doi.org/10.1029/2003JD003535

Shutts, G. J., and Vosper, S. B. (2011). Stratospheric gravity waves revealed in NWP model forecasts. Quart. J. Roy. Meteor. Soc., 137(655), 303-317. https://doi.org/10.1002/qj.763

Spiga, A., Teitelbaum, H., and Zeitlin, V. (2008). Identification of the sources of inertia-gravity waves in the Andes Cordillera region. Ann. Geophys., 26(9), 2551-2568. https://doi.org/10.5194/angeo-26-2551-2008

Thomas, L., Worthington, R. M., and McDonald, A. J. (1999). Inertia-gravity waves in the troposphere and lower stratosphere associated with a jet stream exit region. Ann. Geophys., 17(1), 115-121. https://doi.org/10.1007/s00585-999-0115-4

Vaughan, G., and Worthington, R. M. (2007). Inertia-gravity waves observed by the UK MST radar. Quart. J. Roy. Meteor. Soc., 133(S2), 179-188. https://doi.org/10.1002/qj.142

Xia, H. Y., Dou, X. K., Sun, D. S., Shu, Z. F., Xue, X. H., Han, Y., Hu, D. D., Han, Y. L., and Cheng, T.D. (2012). Mid-altitude wind measurements with mobile Rayleigh Doppler LiDAR incorporating system-level optical frequency control method. Opt. Express, 20(14), 15286-15300. https://doi.org/10.1364/OE.20.015286

Zhao, R. C., Dou, X. K., Sun, D. S., Xue, X. H., Zheng, J., Han, Y. L., Chen, T. D., Wang, G. C., and Zhou, Y. J. (2016). Gravity waves observation of wind field in stratosphere based on a Rayleigh Doppler LiDAR. Opt. Express, 24(6), A581-A591. https://doi.org/10.1364/OE.24.00A581

Zhao, R. C., Dou, X. K., Xue, X. H., Sun, D. S., Han, Y. L., Chen, C., Zheng, J., Li, Z. M., Zhou, A. R., ... Chen, T. D. (2017). Stratosphere and lower mesosphere wind observation and gravity wave activities of the wind field in China using a mobile Rayleigh Doppler LiDAR. J. Geophys. Res. Space Phys., 122(8), 8847-8857. https://doi.org/10.1002/2016JA023713 